\title{
RNA-Binding Protein Musashi Homolog 1
}

National Cancer Institute

\section{Source}

National Cancer Institute. RNA-Binding Protein Musashi Homolog 1. NCI Thesaurus. Code $C 74473$.

RNA-binding protein Musashi homolog 1 (362 aa, 39 kDa) is encoded by the human MSI1 gene. This protein is involved in translational modulation through mRNA binding. 